Article

\title{
Access to Mental Health Care during the First Wave of the COVID-19 Pandemic in Italy: Results from the COMET Multicentric Study
}

\author{
Giulia Menculini ${ }^{1, *}$, Alfonso Tortorella ${ }^{1}$, Umberto Albert ${ }^{2,3}{ }^{\oplus}$, Claudia Carmassi ${ }^{4}{ }^{(0}$, Giuseppe Carrà ${ }^{5}$, \\ Francesca Cirulli ${ }^{6}{ }^{\circ}$, Bernardo Dell'Osso ${ }^{7,8}$, Mario Luciano ${ }^{9}{ }^{(}$, , Maria Giulia Nanni ${ }^{10}$, Maurizio Pompili ${ }^{11}{ }^{\circ}$, \\ Gabriele Sani ${ }^{12,13}$, Umberto Volpe ${ }^{14}$, Andrea Fiorillo ${ }^{9}$ and Gaia Sampogna 9
}

\section{check for} updates

Citation: Menculini, G.; Tortorella, A.; Albert, U.; Carmassi, C.; Carrà, G.; Cirulli, F.; Dell'Osso, B.; Luciano, M.; Nanni, M.G.; Pompili, M.; et al. Access to Mental Health Care during the First Wave of the COVID-19 Pandemic in Italy: Results from the COMET Multicentric Study. Brain Sci. 2021, 11, 1413. https://doi.org/ $10.3390 /$ brainsci11111413

Academic Editor: Rosemary Sheehan

Received: 22 September 2021

Accepted: 22 October 2021

Published: 26 October 2021

Publisher's Note: MDPI stays neutral with regard to jurisdictional claims in published maps and institutional affiliations.

Copyright: (c) 2021 by the authors. Licensee MDPI, Basel, Switzerland. This article is an open access article distributed under the terms and conditions of the Creative Commons Attribution (CC BY) license (https:/ / creativecommons.org/licenses/by/ $4.0 /)$.
1 Department of Psychiatry, University of Perugia, Piazza Lucio Severi 1, 06132 Perugia, Italy; alfonso.tortorella@unipg.it

2 Department of Medicine, Surgery and Health Sciences, University of Trieste, 34128 Trieste, Italy; ualbert@units.it

3 Department of Mental Health, Psychiatric Clinic, Azienda Sanitaria Universitaria Giuliano-Isontina-ASUGI, 34128 Trieste, Italy

4 Department of Clinical and Experimental Medicine, University of Pisa, 56126 Pisa, Italy; ccarmassi@gmail.com

5 Department of Medicine and Surgery, University of Milan Bicocca, 20126 Milano, Italy; giuseppe.carra@unimib.it

6 Center for Behavioral Sciences and Mental Health, National Institute of Health, 00161 Rome, Italy; francesca.cirulli@iss.it

7 Department of Biomedical and Clinical Sciences "Luigi Sacco", University of Milan, 20157 Milan, Italy; bernardo.dellosso@unimi.it

8 Department of Health Sciences, Aldo Ravelli Center for Neurotechnology and Brain Therapeutic, University of Milan, 20142 Milan, Italy

9 Department of Psychiatry, University of Campania Luigi Vanvitelli, Largo Madonna delle Grazie, 80138 Naples, Italy; mario.luciano@unicampania.it (M.L.); andrea.fiorillo@unicampania.it (A.F.); gaia.sampogna@unicampania.it (G.S.)

10 Department of Biomedical and Specialty Surgical Sciences, Institute of Psychiatry, University of Ferrara, 44121 Ferrara, Italy; nnnmgl@unife.it

11 Department of Neurosciences, Mental Health and Sensory Organs, Faculty of Medicine and Psychology, Sapienza University of Rome, 00185 Rome, Italy; maurizio.pompili@uniroma1.it

12 Department of Neuroscience, Section of Psychiatry, University Cattolica del Sacro Cuore, 00168 Rome, Italy; gabriele.sani@unicatt.it

13 Department of Psychiatry, Fondazione Policlinico Agostino Gemelli IRCCS, 00168 Rome, Italy

14 Clinical Psychiatry Unit, Department of Clinical Neurosciences, Università Politecnica delle Marche, 60121 Ancona, Italy; u.volpe@staff.univpm.it

* Correspondence: giuliamenculini@gmail.com; Tel.: +39-075-578-3194

Abstract: The COVID-19 pandemic represents an unprecedented public health emergency, with consequences at the political, social, and economic levels. Mental health services have been called to play a key role in facing the impact of the pandemic on the mental health of the general population. In the period March-May 2020, an online survey was implemented as part of the Covid Mental Health Trial (COMET), a multicentric collaborative study carried out in Italy, one of the Western countries most severely hit by the pandemic. The present study aims to investigate the use of mental health resources during the first wave of the pandemic. The final sample consisted of 20,712 participants, mainly females $(N=14,712,71 \%)$ with a mean age of $40.4 \pm 14.3$ years. Access to mental health services was reported in $7.7 \%$ of cases. Among those referred to mental health services, in $93.9 \%$ of cases ( $N=1503$ subjects) a psychological assessment was requested and in $15.7 \%$ of cases $(N=252)$ a psychiatric consultation. People reporting higher levels of perceived loneliness (OR 1.079, 95\% CI 1.056-1.101, $p<0.001$ ), practicing smart-working (OR 1.122, 95\% CI 0.980-1.285, $p=0.095)$, using avoidant (OR 1.586, 95\% CI 1.458-1.725, $p<0.001$ ) and approach (OR 1.215, 95\% CI 1.138-1.299, $p<0.001)$ coping strategies more frequently accessed mental health services. On the other hand, having higher levels of perceived social support (OR 0.833, 95\% CI 0.795-0.873, $p<0.001)$ was associated with a reduced probability to access mental health services. The COVID-19 
pandemic represents a new threat to the mental health and well-being of the general population, therefore specific strategies should be implemented to promote access to mental healthcare during the pandemic and afterwards.

Keywords: COVID-19; lockdown; access to care; mental health services; psychiatric care; stress; loneliness

\section{Introduction}

The COVID-19 pandemic represents an unprecedented public health emergency, with consequences at the political, social, and economic levels [1]. Since the pandemic onset, mental health has been seriously affected [2,3] due to the fear of contagion, social isolation, and lockdown measures [4]. In particular, home confinement and quarantine have led to prolonged separation from relatives and loved ones [5,6], contributing to increasing the levels of distress not only for people with pre-existing mental disorders, but also for those affected by COVID-19, healthcare professionals, and the general population as a whole [7-11]. Furthermore, the SARS-CoV-2 also presents neurotropism and may thus directly trigger possible neuropsychiatric manifestations [12-14]. The effects of the COVID19 pandemic on mental health include the rise of anxiety and depressive symptoms, somatic complaints $[6,15,16]$, disruption of circadian rhythms, with frequent sleep disorders [17], phobias, cognitive deficits, and traumatic experiences.

In this scenario, mental health services have been called to play a key role in order to support not only people with mental disorders, but also "new users" from the general population exposed to the impact of the pandemic $[4,18,19]$. As a direct consequence of the pandemic and its related containment measures, a substantial reorganization of mental health care has been needed, with the implementation of telemedicine and at-distance consultation [20-23]. Indeed, remote psychiatric consultations and online psychotherapies have been rapidly implemented, which have been found to be effective [24-26]; however, the use of web-based interventions poses major challenges due to disparities in internet access, abilities in using technology, and privacy concerns [21,27-29].

During the first weeks of the pandemic, a significant reduction in accessing emergency rooms [30-32] and in psychiatric hospitalization rates [31,33] was documented in both the United States and European countries, including Italy. Moreover, a mean decrease of 37\% in overall access to healthcare has been reported worldwide, both in outpatient visits and inpatient admissions to different healthcare services [34,35]. The reduced access rate to healthcare could be due to the fear of being infected and to the practical difficulties in reaching services (i.e., due to quarantine or home confinement) $[19,21]$. Furthermore, in general hospitals, health professionals were redistributed due to special needs associated with the creation of COVID-19-dedicated services [36]. In particular, for mental health services, the reduction in access rate has been more pronounced, also due to stigma and discriminating behaviors [37,38], which got even worse during the pandemic $[39,40]$. Stigma was listed among the main stressors for subjects suffering from psychiatric disorders [41], but it also affected the general population [5]. It is well known that stigma significantly limits access to care, as a consequence of reduced self-esteem, poor sense of empowerment, and low illness acceptance [42-44].

A few studies have assessed the use of mental health resources, especially during the first wave of the pandemic. Most evidence relies on qualitative reports from populations of service users or from data coming from limited settings, i.e., emergency departments [45-48]. An in-depth description of the use of mental health services during the COVID-19 pandemic is necessary in order to delineate new pathways to care and to develop supportive interventions for the general population [11,49].

Based on these premises, the aims of the present study were: (1) to evaluate the use of mental health resources during the first pandemic wave among the Italian general population; (2) to identify factors associated with access to mental health services. We 
expect to find an association between referrals to mental health resources during the pandemic and both environmental factors (i.e., financial consequences of COVID-19) and psychopathological features (i.e., presence of a previous mental disorders, insomnia, and depressive symptoms).

\section{Materials and Methods}

\subsection{Study Design and Procedures}

The present study is part of the COMET trial, a multicenter project coordinated by the University of Campania "Luigi Vanvitelli" (Naples). Nine university sites participated in the study, namely Università Politecnica delle Marche (Ancona), University of Ferrara, University of Milan Bicocca, University of Milan "Statale", University of Perugia, University of Pisa, Sapienza University of Rome, "Catholic" University of Rome, University of Trieste. The Center for Behavioral Sciences and Mental Health of the National Institute of Health in Rome also provided support in the dissemination and implementation of the project in accordance with the clinical guidelines of the National Institute of Health for managing the effects of the COVID-19 pandemic. The study has been approved by the Ethical Review Board of the coordinating center (protocol number: 0007593/i).

The COMET trial includes three different phases, which have already been described elsewhere [6,40]. The survey was carried out between March and May 2020, and it was disseminated through different channels, particularly: (a) email invitation to healthcare professionals and their patients; (b) social medias (Facebook, Twitter, Instagram); (c) mailing lists of universities, national medical associations, and associations of stakeholders (i.e., associations of users/caregivers); and (d) other official websites (i.e., healthcare or welfare authorities' websites). The online survey was launched through EUSurvey, a web platform promoted by the European Commission, and it took from 15 to $45 \mathrm{~min}$ to be filled.

\subsection{Assessment Tools}

Participants to the survey completed an ad-hoc schedule for collecting socio-demographic and clinical information, including the presence of a pre-existing mental or physical disorder, having been infected by COVID-19 or subjected to quarantine, and patterns of internet and web-resources use. The main outcome of this paper, namely the use of mental health resources by the general population, was investigated by two ad-hoc questions ("Since the beginning of the pandemic, did you attend a psychiatric consultation?", and "Since the beginning of the pandemic, did you attend counselling/psychological consultation?"). Possible answers were "Yes" or "No" for both questions. The two items were collapsed into a single item, considered a proxy for access to mental health resources during the pandemic.

The psychopathological assessment included the Depression, Anxiety, Stress Scale (DASS-21) [50], the Insomnia Severity Index (ISI) [51], the Brief-COPE, the Multidimensional Scale of Perceived Social Support (MSPSS), the UCLA loneliness scale-short version, the Impact of Event Scale (IES)—-short version, the Severity of Acute Stress Symptom scale (SASS), the Post-Traumatic Growth Inventory (PTGI)-short form, and the ObsessiveCompulsive Inventory-Revised version (OCI-R). The DASS-21 includes 21 items grouped in three subscales, namely, depression, anxiety, and stress. Each item is rated on a 4-level Likert scale from 0 (never) to 3 (almost always). The DASS-21 total score can be obtained from the sum of the response values of each item and higher scores suggest more severe levels of depressive, anxiety, and stress symptoms [41]. The ISI is a brief instrument assessing different components of insomnia. It includes seven items rated on a 5-level Likert scale, with a total score ranging from 0 to 28 and higher scores indicating higher severity of insomnia [42]. The Brief-COPE consists of 28 items rated on a 4-level Likert scale. Coping strategies are divided in maladaptive (denial, venting, behavioral disengagement, self-blame, self-distraction, and substance abuse) and adaptive (emotional support, use of information, positive reframing, planning, and acceptance) strategies. Two other subscales include religion and humor [52]. The COPE-avoidant score is represented by the mean 
score at the maladaptive strategies subscales, whilst for obtaining the COPE-approach score the mean of adaptive subscales is considered [53]. The MSPSS consists of 12 items rated on a 7-level Likert scale, which are categorized into three dimensions, namely, family support, support by friends, and support by significant others. Higher scores identify higher levels of perceived support [54]. The UCLA loneliness scale-short version is an instrument conceived to measure feelings of loneliness and social isolation, which is composed of eight items scored on a 4-level Likert scale. Although no clinically meaningful cutoffs have been established for this scale, higher scores account for higher levels of loneliness [55]. The IESshort version assesses psychological reactions in people who have experienced traumatic events, investigating the dimensions of intrusion, avoidance, and arousal disturbances. It consists of 6 items rated on a 5-point Likert scale [56]. The SASS assesses acute traumatic stress-related symptoms and consists of seven items rated on a 5-point scale, with higher scores indicating a greater severity of acute stress disorders [57]. The short form of the Post-Traumatic Growth Inventory (PTGI) is a 10-item assessment instrument subdivided into five dimensions: relating to others, new possibilities, personal strengths, spiritual change, and appreciation of life. Items are scored on a 6-point Likert scale, with higher scores indicating higher levels of post-traumatic growth [58]. The OCI-R is an 18-item assessment instrument exploring the main symptom dimensions of obsessive-compulsive disorder (OCD), including checking, washing, ordering, hoarding, obsessing, and neutralizing. Items are rated on a 5-level Likert scale from 0 to 4 and the total score is calculated by adding all single items. A cutoff of 21 has been established for the diagnosis of OCD [59]. Further measures included in the COMET assessment and described elsewhere [60] were the General Health Questionnaire-12 items version (GHQ) [61], the Connor-Davidson Resilience Scale (CD-RISC), the Suicidal Ideation Attributes Scale (SIDAS) [62], and the Maslach Burnout Inventory (MBI) [63]. The assessment tools included in the COMET study are summarized in Table 1.

Table 1. Clinical scales used for psychopathological assessment in the COMET trial.

\begin{tabular}{|c|c|c|c|}
\hline Assessment Tool & Structure & $\begin{array}{l}\text { Considered } \\
\text { Time Frame }\end{array}$ & Scoring \\
\hline $\begin{array}{l}\text { Depression, Anxiety, Stress Scale } \\
\text { (DASS-21) }\end{array}$ & $\begin{array}{c}21 \text { items } \\
\text { 4-point scale (0-3) } \\
\text { Three subscales (depression, anxiety, stress) }\end{array}$ & Last week & $\begin{array}{l}\text { Sum of item scores } \\
\text { Higher scores }=\text { higher severity }\end{array}$ \\
\hline Insomnia Severity Index (ISI) & $\begin{array}{l}7 \text { items } \\
\text { 5-point scale }(0-4)\end{array}$ & Last two weeks & $\begin{array}{c}\text { Sum of items scores } \\
\text { Score } \geq 15=\text { clinically relevant insomnia }\end{array}$ \\
\hline Brief-COPE & $\begin{array}{c}21 \text { items } \\
\text { 4-point scale } \\
\text { Two subscales (approach, avoidant) plus } \\
\text { religion and humor }\end{array}$ & Lifetime & $\begin{array}{l}\text { Mean score of the items belonging to } \\
\text { each subscale } \\
\text { Higher scores = higher tendency to use } \\
\text { the coping strategy }\end{array}$ \\
\hline $\begin{array}{l}\text { Multidimensional Scale of } \\
\text { Perceived Social Support (MSPSS) }\end{array}$ & $\begin{array}{c}\text { 21 items } \\
\text { 7-point scale (1-7) } \\
\text { Three dimensions (support from family, } \\
\text { friends, significant others) }\end{array}$ & Lifetime & $\begin{array}{l}\text { Mean score of items (both for total score } \\
\text { and dimensional scores) } \\
\text { Higher scores = higher perceived social } \\
\text { support }\end{array}$ \\
\hline UCLA loneliness scale & $\begin{array}{l}8 \text { items } \\
\text { 4-point scale }(1-4)\end{array}$ & Lifetime & $\begin{array}{l}\text { Sum of item scores (range 8-32) } \\
\text { Higher scores }=\text { higher levels of } \\
\text { perceived loneliness }\end{array}$ \\
\hline $\begin{array}{c}\text { Impact of Event Scale (IES)—short } \\
\text { version }\end{array}$ & $\begin{array}{c}6 \text { items } \\
\text { 5-point scale (0-4) } \\
\text { Three dimensions (intrusion, avoidance, } \\
\text { arousal disturbances) }\end{array}$ & Last week & $\begin{array}{l}\text { Mean of item scores } \\
\text { Higher scores = higher symptom } \\
\text { severity }\end{array}$ \\
\hline $\begin{array}{c}\text { Severity of Acute Stress Symptom } \\
\text { scale (SASS) }\end{array}$ & $\begin{array}{l}9 \text { items } \\
\text { 5-point scale }(0-4)\end{array}$ & Last week & $\begin{array}{l}\text { Sum of item scores (also possible to } \\
\text { calculate an average score) } \\
\text { Higher scores = higher symptom } \\
\text { severity }\end{array}$ \\
\hline $\begin{array}{l}\text { Post-Traumatic Growth Inventory } \\
\text { (PTGI)—short form }\end{array}$ & $\begin{array}{l}10 \text { items } \\
\text { 6-point scale }(0-5) \\
\text { Five dimensions: relating to others, new } \\
\text { possibilities, personal strengths, spiritual } \\
\text { change, appreciation of life }\end{array}$ & Lifetime & $\begin{array}{l}\text { Sum of item scores } \\
\text { Higher scores = higher levels of } \\
\text { post-traumatic growth }\end{array}$ \\
\hline
\end{tabular}


Table 1. Cont.

\begin{tabular}{|c|c|c|c|}
\hline Assessment Tool & Structure & $\begin{array}{l}\text { Considered } \\
\text { Time Frame }\end{array}$ & Scoring \\
\hline $\begin{array}{c}\text { Obsessive-Compulsive } \\
\text { Inventory_Revised version } \\
\text { (OCI-R) }\end{array}$ & $\begin{array}{l}18 \text { items } \\
\text { 5-point scale }(0-4)\end{array}$ & Last month & $\begin{array}{l}\text { Sum of item scores } \\
\text { Score } \geq 21: \text { diagnosis of CD }\end{array}$ \\
\hline $\begin{array}{l}\text { General Health } \\
\text { Questionnaire-12 items (GHQ) }\end{array}$ & $\begin{array}{c}12 \text { items } \\
\text { (6 positively worded, } 6 \text { negatively worded) } \\
\text { 4-point scale }(0-3)\end{array}$ & Last two weeks & $\begin{array}{c}\text { First two types of answers: } 0 \text { (positive); } \\
\text { last two types of answers: score } 1 \\
\text { (negative) } \\
\text { Score } \geq 4 \text { : probability }>80 \% \text { of having a } \\
\text { mental health problem }\end{array}$ \\
\hline $\begin{array}{l}\text { Connor-Davidson Resilience Scale } \\
\text { (CD-RISC) }\end{array}$ & $\begin{array}{l}10 \text { items } \\
\text { 6-point scale (0-5) } \\
\text { Five factors: personal competence, high } \\
\text { standards, and tenacity; trust in one's } \\
\text { instincts, tolerance of negative affect, and } \\
\text { strengthening effects of stress; positive } \\
\text { acceptance of change and secure } \\
\text { relationships; control; spiritual influences }\end{array}$ & Last month & $\begin{array}{l}\text { Sum of item scores } \\
\text { Higher scores = higher levels of } \\
\text { resilience }\end{array}$ \\
\hline $\begin{array}{l}\text { Suicidal Ideation Attributes Scale } \\
\text { (SIDAS) }\end{array}$ & $\begin{array}{c}5 \text { items } \\
\text { 10-point scale (0-10) } \\
\text { Frequency, controllability, closeness to } \\
\text { attempt, distress, interference with daily } \\
\text { activities }\end{array}$ & Last month & $\begin{array}{l}\text { Sum of item scores (if item } 1 \text { is scored } 0 \text {, } \\
\text { all the others are skipped; controllability: } \\
\text { reverse score) } \\
\text { Higher scores }=\begin{array}{r}\text { greater suicidal ideation } \\
\text { severity }\end{array}\end{array}$ \\
\hline Maslach Burnout Inventory (MBI) & $\begin{array}{c}22 \text { items } \\
\text { 7-point scale (0-6) } \\
\text { Three subscales (emotional exhaustion, } \\
\text { depersonalization, personal } \\
\text { accomplishment) }\end{array}$ & $\begin{array}{l}\text { Lifetime (as long } \\
\text { as it applies) }\end{array}$ & $\begin{array}{l}\text { Sum of item scores for each subscale (no } \\
\text { total score) } \\
\text { Higher scores = higher levels of burnout } \\
\text { for emotional exhaustion and } \\
\text { depersonalization subscales, reverse for } \\
\text { personal accomplishment }\end{array}$ \\
\hline
\end{tabular}

\subsection{Statistical Analysis}

Descriptive analyses were carried out in order to evaluate the distribution of sociodemographic and clinical characteristics in the sample. Differences in those accessing mental health services compared to the remaining sample were analyzed using a chi-square test for categorical variables and Student's $t$-test for continuous variables. Given the large sample size, a parametric technique was chosen due to its sensitivity and since it guarantees sufficient robustness even in case of normality assumption violation [64-66]. A multivariate logistic regression model was implemented in order to evaluate the association between use of mental health resources and other significant independent variables, namely, diagnosis of a psychiatric disorder, being a health professional, being unemployed, being in smart-working, scores on the DASS-21, ISI, COPE-avoidant, COPE-approach, MSPSS, and UCLA. The model was adjusted for the period when the interview was administered, for gender, and for age. Odds ratios (OR) with 95\% confidence intervals were assessed for observed associations. All tolerance values in the regression analyses were $>0.2$ and all variance inflation factors were $<2$, indicating that multicollinearity was not a source of bias in the regression model. Statistical analyses were performed using the Statistical Package for Social Sciences (SPSS) for Windows, version 21. All $p$-values were 2-tailed, and statistical significance was set at $p<0.05$.

\section{Results}

\subsection{Sociodemographic and Clinical Characteristics}

The whole sample consisted of 20,720 subjects. Eight participants were excluded, since they did not answer the specific questions on the use of mental health services. Therefore, the final sample consisted of 20,712 participants. Among these, $14,712(N=71 \%)$ were females, with a mean age of $40.42 \pm 14.32$ years. All socio-demographic characteristics of the COMET trial population are described in detail elsewhere [6]. 
Since the beginning of the pandemic, $1601(7.7 \%)$ participants have had a contact with mental health services. In particular, 1503 subjects (93.9\%) requested a psychological assessment and $252(15.7 \%)$ underwent a psychiatric consultation. Moreover, $11.8 \%$ $(N=189)$ of participants who accessed mental health services were health professionals; $7.4 \%(N=119)$ suffered from a pre-existing mental disorder; $5.9 \%(N=94)$ of subjects belonging to this subpopulation lost their job due to the pandemic, while $35.6 \%(N=570)$ shifted to smart-working. In the overall sample of subjects referring to mental health services, about one-third of participants were satisfied with their economic condition $(N=434,27.1 \%)$ or living condition $(N=582,36.4 \%)$. None of the respondents receiving a mental health consultation had spent more time on the Internet since the beginning of the pandemic. Only $1.2 \%(N=20)$ of people seen in psychiatric services had been affected by COVID-19, while $4.7 \%(N=75)$ of them had been subjected to quarantine measures.

\subsection{Comparisons between Subjects Referring or Not Referring to Mental Health Services}

Unemployment $(11.4 \%$ vs. $9.1 \%, p=0.003)$ and smart-working rates $(51.9 \%$ vs. $48.6 \%$, $p=0.038$ ) were higher in subjects referring to mental health services compared to the remaining sample. No other statistically significant socio-demographic difference was found between the two groups. The use of mental health services did not differ according to the weeks of the lockdown nor to the geographic area of participants.

People accessing mental health services reported higher levels of stress $(8.4 \pm 3.4$ vs. $8.1 \pm 3.6, p=0.005)$, anxiety $(4.0 \pm 3.5$ vs. $3.7 \pm 3.4, p=0.001)$, and depression ( $6.4 \pm 3.7$ vs. $6.1 \pm 3.8, p=0.001)$ on the DASS-21 compared to those not accessing those services. Subjects in this subgroup also reported higher levels of insomnia (ISI mean score $7.1 \pm 5.4$ vs. $6.8 \pm 5.2, p=0.009$ ). As for coping strategies, the mean scores of both the COPE-avoidant and COPE-approach subscales were higher in subjects who sought mental healthcare during the lockdown (COPE-avoidant mean score: $4.25 \pm 0.8$ vs. $3.85 \pm 0.8$, $p<0.001$; COPE-approach mean score: $5.68 \pm 1$ vs. $5.50 \pm 1, p<0.001)$ compared to the remaining sample. Moreover, those people also reported lower levels of perceived social support (MSPSS mean score: $4.9 \pm 1.4$ vs. $5.3 \pm 1.3, p<0.001$ ) and higher levels of perceived loneliness (UCLA mean score: $12.5 \pm 3.3$ vs. $11.2 \pm 3.2, p<0.001$ ) (Table 2).

\subsection{Factors Associated with the Use of Mental Health Services during the Pandemic}

When performing a multivariate logistic regression with the use of mental health resources as a dependent variable, the model $\left(\chi^{2}(13)=442.629, p<0.001\right)$ explained between $3 \%$ and $7.2 \%$ of the variance. Variables that showed a significant positive association with the use of mental health services during the pandemic were the UCLA total score (OR 1.079, 95\% CI 1.056-1.101, $p<0.001$ ), the COPE avoidant (OR 1.586, 95\% CI 1.458-1.725, $p<0.001$ ) and approach (OR 1.215, 95\% CI 1.138-1.299, $p<0.001$ ) subscales, and doing smart-working (OR 1.122, 95\% CI 0.980-1.285, $p=0.095$ ). Being a health care professional (OR $0.841,95 \%$ CI $0.744-1.008, p=0.061$ ) and having higher levels of social support (OR $0.833,95 \% \mathrm{CI}$ $0.795-0.873, p<0.001)$ were protective factors against the likelihood of contacting mental health services (Table 3). These results did not change after controlling for age, gender, and for the period of time when the interview was administered. 
Table 2. Comparison of socio-demographic, clinical and psychopathological characteristics of subjects who attended a psychiatric or psychological visit (mental health users, MHU, $N=1601,7.7 \%$ ) during the first COVID-19 pandemic wave and those who did not.

\begin{tabular}{|c|c|c|c|c|c|}
\hline & Total Sample $(N, \%)$ & $\operatorname{MHU}(N, \%)$ & $\mathrm{nMHU}(N, \%)$ & $x^{2}$ & $p$ \\
\hline \multicolumn{6}{|l|}{ Socio-demographic features } \\
\hline Female gender & $14,712(71)$ & $1167(72.9)$ & $13,545(70.9)$ & 2.822 & 0.093 \\
\hline $\begin{array}{l}\text { High impact region (Emilia-Romagna, } \\
\text { Lombardia, Piedmont, Veneto) }\end{array}$ & $6470(31.2)$ & $514(32.1)$ & $5956(31.2)$ & 0.564 & 0.453 \\
\hline Marital status: single & $8092(39.1)$ & $649(40.5)$ & $7443(38.9)$ & 1.505 & 0.220 \\
\hline Scholarity $>13$ years & $12,839(62)$ & $979(61.1)$ & $11,860(62.1)$ & 0.480 & 0.488 \\
\hline Working status: student & $4846(23.4)$ & $384(24)$ & $4462(23.3)$ & 0.300 & 0.584 \\
\hline Working status: unemployed & $1924(9.3)$ & $182(11.4)$ & $1742(9.1)$ & 8.631 & 0.003 \\
\hline Smart-working & $7085(48.9)$ & $570(51.9)$ & $6515(48.6)$ & 4.322 & 0.038 \\
\hline \multirow{2}{*}{ Health professional } & $2905(14)$ & $189(11.8)$ & $2716(14.2)$ & 6.897 & 0.009 \\
\hline & Total sample (mean, SD) & MHU (mean, SD) & nMHU (mean, SD) & $t$ & $p$ \\
\hline Age & $40.42(14.32)$ & $40.22(14.40)$ & $40.44(14.31)$ & 0.584 & 0.559 \\
\hline \multirow{2}{*}{ Number of cohabitants } & $2.82(1.37)$ & $2.86(1.34)$ & $2.81(1.37)$ & -1.281 & 0.200 \\
\hline & Total sample $(N, \%)$ & $\operatorname{MHU}(N, \%)$ & nMHU $(N, \%)$ & $x^{2}$ & $p$ \\
\hline \multicolumn{6}{|l|}{ Clinical features } \\
\hline Pre-existing psychiatric disorder & $1133(5.5)$ & $119(7.4)$ & $1014(5.3)$ & 12.516 & $<0.001$ \\
\hline \multirow[t]{2}{*}{ Pre-existing medical illness } & $3012(14.5)$ & $247(15.4)$ & $2765(14.5)$ & 1.019 & 0.313 \\
\hline & Total sample (mean, SD) & MHU (mean, SD) & nMHU (mean, SD) & $t$ & $p$ \\
\hline \multirow[t]{2}{*}{ Number of hours spent on internet } & $4.84(2.30)$ & $4.97(3.13)$ & $4.82(2.99)$ & -1.894 & 0.058 \\
\hline & Total sample $(N, \%)$ & $\operatorname{MHU}(N, \%)$ & nMHU $(N, \%)$ & $\chi^{2}$ & $p$ \\
\hline \multirow{4}{*}{$\begin{array}{c}\text { Pandemic-related features } \\
\text { Survey taken during March/first half of April } \\
\text { Having themselves/relatives infected or } \\
\text { quarantined }\end{array}$} & & & & & \\
\hline & $15,704(75.8)$ & $1194(74.6)$ & $14,510(75.9)$ & 1.338 & 0.239 \\
\hline & $1088(5.3)$ & $87(5.4)$ & $1001(5.2)$ & 0.078 & 0.780 \\
\hline & Total sample $(N, \%)$ & MHU (mean, SD) & nMHU (mean, SD) & $t$ & $p$ \\
\hline \multicolumn{6}{|l|}{ Psychopathological characteristics } \\
\hline DASS-21 & $18.04(8.40)$ & $18.84(8.19)$ & $17.98(8.41)$ & -4.051 & $<0.001$ \\
\hline ISI & $6.80(5.19)$ & $7.15(5.39)$ & $6.78(5.17)$ & -2.650 & 0.006 \\
\hline Brief-COPE avoidant score & $3.88(0.79)$ & $4.25(0.77)$ & $3.85(0.79)$ & -19.828 & $<0.001$ \\
\hline Brief-COPE approach score & $5.52(1.07)$ & $5.68(1.05)$ & $5.50(1.07)$ & -6.400 & $<0.001$ \\
\hline MSPSS & $5.31(1.36)$ & $4.94(1.45)$ & $5.34(1.35)$ & 10.700 & $<0.001$ \\
\hline UCLA & $11.31(3.26)$ & $12.55(3.35)$ & $11.20(3.23)$ & -15.961 & $<0.001$ \\
\hline SASS & $6.03(4.94)$ & $6.26(4.99)$ & $6.01(4.93)$ & -1.886 & 0.059 \\
\hline IES-R & $1.16(0.86)$ & $1.14(0.86)$ & $1.16(0.86)$ & 0.877 & 0.381 \\
\hline PTGI & $19.02(11.49)$ & $19.19(11.27)$ & $19.01(11.51)$ & -0.595 & 0.552 \\
\hline OCI-R & $10.77(8.51)$ & $11.13(8.82)$ & $10.74(8.48)$ & -1.687 & 0.092 \\
\hline
\end{tabular}

Notes: DASS-21 = Depression, Anxiety, Stress Scale-21 items; IES-R = Impact of Event Scale-short version; ISI = Insomnia Severity Index; MSPSS = Multidimensional Scale of Perceived Social Support; OCI = Obsessive-Compulsive Index-Revised version; PTGI = Post-Traumatic Growth Inventory; SASS = Severity of Acute Stress Symptom scale.

Table 3. Logistic regression analyzing factors associated with access to mental health care resources in the study population. The model was corrected for gender, age, and time when the interview was performed.

\begin{tabular}{cccc}
\hline Variables in Equation & Wald & $p$-Value & OR (95\% CI) \\
\hline 1-4 & 115.086 & $<0.001$ & $1.586(1.458-1.725)$ \\
COPE avoidant & 33.305 & $<0.001$ & $1.215(1.138-1.299)$ \\
Smart-working & 2.785 & 0.095 & $1.122(0.980-1.285)$ \\
UCLA & 51.021 & $<0.001$ & $1.079(1.056-1.101)$ \\
MSPSS & 58.081 & $<0.001$ & $0.833(0.795-0.873)$ \\
Health professional & 3.511 & 0.061 & $0.842(0.704-1.008)$ \\
\hline
\end{tabular}

Variables not in equation: DASS-21 total score; ISI total score; working status: unemployed; pre-existing psychiatric disorder. Chi-square: $442.629 ; d f: 13 ; p<0.001$. 


\section{Discussion}

To the best of our knowledge, our study is one of the first large-scale studies carried out during the first wave of the COVID-19 pandemic focusing on the use of mental health resources. The main outcome of the study was to evaluate the use of mental health services during the first wave of the COVID-19 pandemic. In our sample, $91.2 \%$ of participants were at-risk for developing a mental health problem [60], but only $7.7 \%$ consulted a psychologist or a psychiatrist. This finding is in line with a cross-sectional study conducted in France, where only 3.6\% of subjects in need for psychological help consulted mental health professionals during the lockdown [67]. These data may to some extent mirror results from the World Health Organization's (WHO) survey, where $60 \%$ of participating countries reported disruptions in mental health services for vulnerable populations, whilst $67 \%$ conveyed psychotherapy and counselling services disruption [68]. Furthermore, previous studies described a reduction of psychiatric emergency visits during the first wave of the pandemic [36]. A significant reduction in referrals and self-presentation to community mental health services was also reported in the United Kingdom, without clear evidence of a redistribution of cases among other services [69]. This could be due to both the fear of contagion [70] and the shift towards telemedicine [71,72].

During the first weeks of the pandemic, the reduced access rate to health services was not specific to mental health services, rather it was a global trend [73]. The reorganization of health services and the implementation of extraordinary measures for containing the pandemic may have also had an impact on the access rate, since changes in health resources allocation due to COVID-19 possibly reduced the delivery of specific services, e.g., outpatient visits, to subjects suffering from other diseases [37]. It is noteworthy that Italian data revealed that inpatient admissions were reduced by $17 \%$. In this scenario, digital health interventions were implemented for different medical specialties, but these are still burdened by several matters, such as ethical, legal, and accessibility issues that may account for the underutilization of these resources [74,75]. Telemedicine thus represents a still growing field, which should hopefully be empowered in the near future in order to overcome the above-mentioned shortcomings and reach a higher number of subjects suffering from different conditions.

The effects of the pandemic on vulnerable groups, such as people with pre-existing mental illnesses, are expected to be more severe due to the limited social networks and the presence of several physical comorbidities [76-78]. In our sample, only $10.5 \%$ of people with pre-existing mental disorders accessed mental health services, which is a much lower rate compared to $25 \%$ observed in Canada, both for face-to-face and online consultations [79]. Therefore, our results confirm a reduction in the use of mental health services [80,81]. Moreover, in our sample the presence of a pre-existing mental disorder was not associated with help-seeking behavior, which might be due to the presence of stigmatizing and discriminating attitudes $[8,82,83]$, further nurtured by the fear of the contagion by the virus [84]. There is the need to foster anti-stigma interventions both at the general population level, promoting the public image of psychiatry, as well as at the patient individual level, for challenging internalized stigma [85,86]. Finally, the low access rate to healthcare services found in people with pre-existing mental disorders highlights the need to create specific "soft entry points" for those people, which also represents a high-risk population for the morbidity and mortality related to COVID-19 [69,83,87,88].

Another interesting finding is that unemployment-considered as one of the "proxy" measures of the immediate social consequence of the pandemic-may influence access to mental health services, which is consistent with the finding that economic factors are the main determinants of perceived stress requiring mental health support $[67,89]$. The pandemic caused an unprecedented socio-economic crisis worldwide, with a shortage of financial resources and increase in unemployment rates. Such psychosocial consequences, as witnessed by previous epidemics, may worsen mental health outcomes, increasing the risk of suicide, and contributing to the adoption of specific risky behaviors, such as alcohol and substance abuse [73,90-93]. Global health policies should take into account financial 
aspects as major determinants of mental health and well-being, thus considering economic support as a concrete strategy that could help mitigating the psychiatric consequences of the pandemic.

Among the work-related factors influencing access to mental health services, we found that those practicing smart-working more frequently asked for a visit with a psychiatrist or a psychologist. Smart-working can have negative effects on mental health, as a consequence of reduced physical activity, increased social isolation and perceived loneliness [94]. Furthermore, loneliness and low levels of perceived social support were also significantly associated with access to mental health resources. Loneliness increases the risk of suicidal behaviors and, together with social isolation, is associated with the development of depressive and anxiety symptoms [95-97]. Subsequently, loneliness should be monitored in routine clinical practice, not only by healthcare professionals, representing a new strategy for suicide prevention [98-100].

Insomnia and sleep disturbances represented a significant predictor of access to mental health care services. This was an expected result considering that sleep disturbances and complaints were highly prevalent during the pandemic and were significantly associated with psychological problems in different populations [101-104]. Lockdown measures may have altered circadian rhythms, and particularly sleep-wake pattern, through changes in working habits and levels of diurnal physical activity [105]. In fact, sleep disorders were one of the most common causes of psychiatric consultations during the pandemic [106,107]. Therefore, at the population level, preventive educational interventions focusing on the sleep-wake pattern should be provided on a regular basis [108]. Higher levels of depression, anxiety, and stress symptoms were also reported among mental health services users. Of note, depression and anxiety showed a sharp increase among the general population during the first weeks after the pandemic outbreak [3]. Furthermore, depression was hypothesized to be one of the post-COVID-19 features predicting a higher need for psychological support [109].

In our sample, the presence of post-traumatic symptoms was not associated with the probability to access mental health services, although these symptoms are frequent in COVID-19 survivors [110]. It could be that avoidance symptoms experienced by these patients may limit access to healthcare centers [111]. Similarly, obsessive-compulsive symptoms were not associated with access to mental health care, although a worsening of these symptoms was reported after the pandemic onset [112]. Possibly, obsessions concerning hygiene and contamination, that were demonstrated to be particularly prevalent during the pandemic [113], may have limited access to care. Despite this, mental health care among subjects suffering from obsessive-compulsive disorder should be promoted, also considering that treatment adjustment were pointed out as a priority in this population after the CoV-SARS-2 outbreak [114]. Future studies could shed light on the psychopathological dimensions influencing the emergence of psychological distress during the pandemic, but also on attitudes of subjects towards healthcare, such as emotional dysregulation [115], affective temperaments [116], and health anxiety [117].

Not surprisingly, people using adaptive coping strategies were more likely to access mental health services during the lockdown [118,119]. However, it could be that people receiving adequate professional support are more likely to develop adaptive coping strategies [47]. On the other side, the adoption of avoidant coping strategies may influence the development of psychiatric symptoms, indirectly affecting access to mental health care services [120]. Future studies should clarify the relationship between coping strategies and access to mental health service in the pandemic era $[83,121]$.

The main limitations of the study include the use of an online survey and of the snowball sampling procedure, which may have biased the recruitment process and the generalizability of our findings. Moreover, data concerning the attendance to psychiatric and psychological consultations were retrospectively collected and were not cross-checked with official data from specific settings, e.g., emergency department admissions. This also contributed to the lack of information concerning the reason why consultations were 
requested, preventing researchers from drawing conclusions on causal associations between specific factors, e.g., SARS-CoV-2 infection and economic factors, and access to mental health care.

\section{Conclusions}

The present study highlights that only a minority of subjects suffering from preexisting mental disorders accessed mental health services during the first wave of the pandemic. Our results suggest that specific strategies should be implemented in order to promote pathways to care in the general population. To this effect, the identification of risk and protective factors could help target interventions to vulnerable groups and enhance a personalized approach to treatments both during and in the aftermath of the pandemic.

Author Contributions: Conceptualization, G.S. (Gaia Sampogna) and A.F.; methodology, M.L.; formal analysis, G.M.; investigation, A.T., U.A., C.C., G.C., F.C., B.D., M.P., M.G.N., G.S. (Gabriele Sani) and U.V.; writing—original draft preparation, G.M. and G.S. (Gaia Sampogna); writing—review and editing, A.T., A.F., U.A., C.C., G.C., F.C., B.D., M.G.N., M.P., G.S. (Gabriele Sani) and U.V. All authors have read and agreed to the published version of the manuscript.

Funding: This research received no external funding.

Institutional Review Board Statement: The study was conducted according to the guidelines of the Declaration of Helsinki and approved by the Institutional Review Board of University of Campania “L. Vanvitelli" (protocol number: 0007593/I, date of approval: 30 March 2020).

Informed Consent Statement: Informed consent was obtained from all subjects involved in the study.

Data Availability Statement: The data presented in this study are available on request from the corresponding author.

Conflicts of Interest: The authors declare no conflict of interest related with the present research.

\section{References}

1. Adhanom Ghebreyesus, T. Addressing mental health needs: An integral part of COVID-19 response. World Psychiatry 2020, 19, 129-130. [CrossRef]

2. Shigemura, J.; Ursano, R.J.; Morganstein, J.C.; Kurosawa, M.; Benedek, D.M. Public responses to the novel 2019 coronavirus (2019-nCoV) in Japan: Mental health consequences and target populations. Psychiatry Clin. Neurosci. 2020, 74, 281-282. [CrossRef] [PubMed]

3. Li, J.; Yang, Z.; Qiu, H.; Wang, Y.; Jian, L.; Ji, J.; Li, K. Anxiety and depression among general population in China at the peak of the COVID-19 epidemic. World Psychiatry 2020, 19, 249-250. [CrossRef]

4. Marazziti, D.; Stahl, S.M. The relevance of COVID-19 pandemic to psychiatry. World Psychiatry 2020, 19, 261. [CrossRef] [PubMed]

5. Brooks, S.K.; Webster, R.K.; Smith, L.E.; Woodland, L.; Wessely, S.; Greenberg, N.; Rubin, G.J. The psychological impact of quarantine and how to reduce it: Rapid review of the evidence. Lancet 2020, 395, 912-920. [CrossRef]

6. Fiorillo, A.; Sampogna, G.; Giallonardo, V.; Del Vecchio, V.; Luciano, M.; Albert, U.; Carmassi, C.; Carrà, G.; Cirulli, F.; Dell'Osso, B.; et al. Effects of the lockdown on the mental health of the general population during the COVID-19 pandemic in Italy: Results from the COMET collaborative network. Eur. Psychiatry 2020, 63, e87. [CrossRef] [PubMed]

7. Moore, R.C.; Depp, C.A.; Harvey, P.D.; Pinkham, A.E. Assessing the real-time mental health challenges of COVID-19 in individuals with serious mental illnesses: Protocol for a quantitative study. JMIR Res. Protoc. 2020, 9, e19203. [CrossRef] [PubMed]

8. Yao, H.; Chen, J.H.; Xu, Y.F. Patients with mental health disorders in the COVID-19 epidemic. Lancet Psychiatry 2020,7 , e21. [CrossRef]

9. Hayat, K.; Arshed, M.; Fiaz, I.; Afreen, U.; Khan, F.U.; Khan, T.A.; Kadirhaz, M.; Shukar, S.; Saeed, A.; Gill, M.R.; et al. Impact of COVID-19 on the Mental Health of Healthcare Workers: A Cross-Sectional Study From Pakistan. Front. Public Health $2021,9,410$. [CrossRef] [PubMed]

10. Reger, M.A.; Stanley, I.H.; Joiner, T.E. Suicide Mortality and Coronavirus Disease 2019-A Perfect Storm? JAMA Psychiatry 2020, 77, 1093-1094. [CrossRef]

11. Fiorillo, A.; Gorwood, P. The consequences of the COVID-19 pandemic on mental health and implications for clinical practice. Eur. Psychiatry 2020, 63, 1-4. [CrossRef]

12. Rogers, J.P.; Chesney, E.; Oliver, D.; Pollak, T.A.; McGuire, P.; Fusar-Poli, P.; Zandi, M.S.; Lewis, G.; David, A.S. Psychiatric and neuropsychiatric presentations associated with severe coronavirus infections: A systematic review and meta-analysis with comparison to the COVID-19 pandemic. Lancet Psychiatry 2020, 7, 611-627. [CrossRef] 
13. Soltani, S.; Tabibzadeh, A.; Zakeri, A.; Zakeri, A.M.; Latifi, T.; Shabani, M.; Pouremamali, A.; Erfani, Y.; Pakzad, I.; Malekifar, P.; et al. COVID-19 associated central nervous system manifestations, mental and neurological symptoms: A systematic review and meta-analysis. Rev. Neurosci. 2021, 32, 351-361. [CrossRef] [PubMed]

14. Slyk, S.; Domitrz, I. Neurological manifestations of SARS-CoV-2-A systematic review. Neurol Neurochir. Pol. 2020, 54, 378-383. [CrossRef]

15. Marroquín, B.; Vine, V.; Morgan, R. Mental health during the COVID-19 pandemic: Effects of stay-at-home policies, social distancing behavior, and social resources. Psychiatry Res. 2020, 293, 113419. [CrossRef] [PubMed]

16. Qiu, J.; Shen, B.; Zhao, M.; Wang, Z.; Xie, B.; Xu, Y. A nationwide survey of psychological distress among Chinese people in the COVID-19 epidemic: Implications and policy recommendations. Gen. Psychiatry 2020, 33, e100213. [CrossRef] [PubMed]

17. Salfi, F.; Lauriola, M.; D'Atri, A.; Amicucci, G.; Viselli, L.; Tempesta, D.; Ferrara, M. Demographic, psychological, chronobiological and work-related predictors of sleep disturbances during the COVID-19 lockdown in Italy. Sci. Rep. 2021, 11, 11416. [CrossRef]

18. Kuzman, M.R.; Curkovic, M.; Wasserman, D. Principles of mental health care during the COVID-19 pandemic. Eur. Psychiatry 2020, 63, e45. [CrossRef]

19. Moesmann Madsen, M.; Dines, D.; Hieronymus, F. Optimizing psychiatric care during the COVID-19 pandemic. Acta Psychiatr. Scand. 2020, 142, 70-71. [CrossRef]

20. Torous, J.; Choudhury, T.; Barnett, I.; Keshavan, M.; Kane, J. Smartphone relapse prediction in serious mental illness: A pathway towards personalized preventive care. World Psychiatry 2020, 19, 308-309. [CrossRef]

21. Goldman, M.L.; Druss, B.G.; Horvitz-Lennon, M.; Norquist, G.S.; Ptakowski, K.K.; Brinkley, A.; Greiner, M.; Hayes, H.; Hepburn, B.; Jorgensen, S.; et al. Mental Health Policy in the Era of COVID-19. Psychiatr. Serv. 2020, 71, 1158-1162. [CrossRef]

22. Carpiniello, B.; Tusconi, M.; Zanalda, E.; Di Sciascio, G.; Di Giannantonio, M. Psychiatry during the Covid-19 pandemic: A survey on mental health departments in Italy. BMC Psychiatry 2020, 20, 1-12. [CrossRef]

23. Stewart, D.E.; Appelbaum, P.S. COVID-19 and psychiatrists' responsibilities: A WPA position paper. World Psychiatry 2020, 19, 406-407. [CrossRef] [PubMed]

24. Cheng, P.; Casement, M.D.; Kalmbach, D.A.; Castelan, A.C.; Drake, C.L. Digital cognitive behavioral therapy for insomnia promotes later health resilience during the coronavirus disease 19 (COVID-19) pandemic. Sleep 2021, 44, zsaa258. [CrossRef] [PubMed]

25. Avalone, L.; Barron, C.; King, C.; Linn-Walton, R.; Lau, J.; McQuistion, H.L.; Popiel, M.; Balasubramaniam, M.; Freeman, R.; Fattal, O. Rapid Telepsychiatry Implementation During COVID-19, Increased Attendance at the Largest Health System in the United States. Psychiatr. Serv. 2021, 72, 708-711. [CrossRef] [PubMed]

26. Stoll, J.; Müller, J.A.; Trachsel, M. Ethical Issues in Online Psychotherapy: A Narrative Review. Front. Psychiatry 2020, 10, 993. [CrossRef]

27. Torous, J.; Andersson, G.; Bertagnoli, A.; Christensen, H.; Cuijpers, P.; Firth, J.; Haim, A.; Hsin, H.; Hollis, C.; Lewis, S.; et al. Towards a consensus around standards for smartphone apps and digital mental health. World Psychiatry 2019, 18, 97-98. [CrossRef]

28. Firth, J.; Torous, J.; Stubbs, B.; Firth, J.A.; Steiner, G.Z.; Smith, L.; Alvarez-Jimenez, M.; Gleeson, J.; Vancampfort, D.; Armitage, C.J.; et al. The "online brain": How the Internet may be changing our cognition. World Psychiatry 2019, 18, 119-129. [CrossRef]

29. Andersson, G.; Titov, N.; Dear, B.F.; Rozental, A.; Carlbring, P. Internet-delivered psychological treatments: From innovation to implementation. World Psychiatry 2019, 18, 20-28. [CrossRef]

30. Holland, K.M.; Jones, C.; Vivolo-Kantor, A.M.; Idaikkadar, N.; Zwald, M.; Hoots, B.; Yard, E.; D’Inverno, A.; Swedo, E.; Chen, M.S.; et al. Trends in US Emergency Department Visits for Mental Health, Overdose, and Violence Outcomes before and during the COVID-19 Pandemic. JAMA Psychiatry 2021, 78, 372-379. [CrossRef] [PubMed]

31. Di Lorenzo, R.; Frattini, N.; Dragone, D.; Farina, R.; Luisi, F.; Ferrari, S.; Bandiera, G.; Rovesti, S.; Ferri, P. Psychiatric emergencies during the COVID-19 pandemic: A 6-month observational study. Neuropsychiatr. Dis. Treat. 2021, 17, 1763-1778. [CrossRef] [PubMed]

32. Appleby, J. What is happening to non-COVID deaths? BMJ 2020, 369, m1607. [CrossRef]

33. Bollmann, A.; Hohenstein, S.; Pellissier, V.; Stengler, K.; Reichardt, P.; Ritz, J.-P.; Thiele, H.; Borger, M.A.; Hindricks, G.; MeierHellmann, A.; et al. Utilization of in- And outpatient hospital care in Germany during the Covid-19 pandemic insights from the German-wide Helios hospital network. PLoS ONE 2021, 16, e0249251. [CrossRef] [PubMed]

34. Moynihan, R.; Sanders, S.; Michaleff, Z.A.; Scott, A.M.; Clark, J.; To, E.J.; Jones, M.; Kitchener, E.; Fox, M.; Johansson, M.; et al Impact of COVID-19 pandemic on utilisation of healthcare services: A systematic review. BMJ Open 2021, 11, e045343. [CrossRef] [PubMed]

35. (OECD) O per la Cooperazione e lo Sviluppo Economico. Strengthening the Frontline: How Primary Health Care Helps Health Systems Adapt during the COVID-19 Pandemic. 2021. Available online: www.oecd.org/coronavirus/policy-responses / strengthening-the-frontline\%02how-primary-health-care-helps-health-systems-adapt-during-the-covid-19-pandemic-9a5ae6 da/ (accessed on 18 August 2021).

36. GIMBE. Impatto della Pandemia COVID-19 Sull'erogazione di Prestazioni Sanitarie; GIMBE: Bologna, Italy, 2021.

37. Schomerus, G.; Baumann, E.; Sander, C.; Speerforck, S.; Angermeyer, M.C. Some good news for psychiatry: Resource allocation preferences of the public during the COVID-19 pandemic. World Psychiatry 2021, 20, 301-302. [CrossRef] [PubMed] 
38. Lynch, L.; Long, M.; Moorhead, A. Young Men, Help-Seeking, and Mental Health Services: Exploring Barriers and Solutions. Am. J. Mens. Health 2018, 12, 138-149. [CrossRef] [PubMed]

39. Saiz, J.; Muñoz, M.; Ausín, B.; González-Sanguino, C.; Castellanos, M.Á.; Vaquero, C.; Ugidos, C.; López-Gómez, A. Effects of COVID-19 lockdown on perceived discrimination and internalized stigma in people with previous mental disorder diagnoses in Spain. Am. J. Orthopsychiatry 2021, 91, 407-411. [CrossRef] [PubMed]

40. Armitage, R.; Nellums, L.B. The COVID-19 response must be disability inclusive. Lancet Public Health 2020, 5, e257. [CrossRef]

41. Kahl, K.G.; Correll, C.U. Management of patients with severe mental illness during the coronavirus disease 2019 pandemic. JAMA Psychiatry 2020, 77, 977-978. [CrossRef] [PubMed]

42. Law, S.; Sirotich, F.; Sunderji, N.; Simpson, A.; Nakhost, A. The relationship between clinician leverage, patient experiences, and the impact of stigma: A study in academic and community outpatient psychiatry settings. Gen. Hosp. Psychiatry 2021, 72, 15-22. [CrossRef]

43. Thornicroft, G. Stigma and discrimination limit access to mental health care. Epidemiol. Psichiatr. Soc. 2008, 17, 14-19. [CrossRef]

44. Alegria, M.; Falgas-Bague, I.; Fong, H. Engagement of ethnic minorities in mental health care. World Psychiatry 2020, 19, 35-36. [CrossRef] [PubMed]

45. Balestrieri, M.; Rucci, P.; Amendola, D.; Bonizzoni, M.; Cerveri, G.; Colli, C.; Dragogna, F.; Ducci, G.; Elmo, M.G.; Ghio, L.; et al. Emergency Psychiatric Consultations During and After the COVID-19 Lockdown in Italy. A Multicentre Study. Front. Psychiatry 2020, 1, 697058. [CrossRef]

46. Ferrando, S.J.; Klepacz, L.; Lynch, S.; Shahar, S.; Dornbush, R.; Smiley, A.; Miller, I.; Tavakkoli, M.; Regan, J.; Bartell, A. Psychiatric emergencies during the height of the COVID-19 pandemic in the suburban New York City area. J. Psychiatr. Res. 2021, 136, 552-559. [CrossRef] [PubMed]

47. Costa, M.; Reis, G.; Pavlo, A.; Bellamy, C.; Ponte, K.; Davidson, L. Tele-Mental Health Utilization Among People with Mental Illness to Access Care During the COVID-19 Pandemic. Community Ment. Health J. 2021, 57, 720-726. [CrossRef] [PubMed]

48. Simpson, S.A.; Loh, R.M.; Cabrera, M.; Cahn, M.; Gross, A.; Hadley, A.; Lawrence, R.E. The Impact of the COVID-19 Pandemic on Psychiatric Emergency Service Volume and Hospital Admissions. J. Acad. Consult. Psychiatry 2021, in press. [CrossRef]

49. Gorwood, P.; Fiorillo, A. One year after the COVID-19: What have we learnt, what shall we do next? Eur. Psychiatry 2021, 64, e15. [CrossRef] [PubMed]

50. Lovibond, S.; Lovibond, P. Manual for the Depression Anxiety \& Stress Scale; Psychology Fundation: Sydney, Australia, 1995.

51. Morin, C.M.; Belleville, G.; Bélanger, L.; Ivers, H. The insomnia severity index: Psychometric indicators to detect insomnia cases and evaluate treatment response. Sleep 2011, 34, 601-608. [CrossRef]

52. Carver, C.S. You want to measure coping but your protocol's too long: Consider the brief COPE. Int. J. Behav. Med. 1997, 4, 92-100. [CrossRef]

53. Eisenberg, S.A.; Shen, B.J.; Schwarz, E.R.; Mallon, S. Avoidant coping moderates the association between anxiety and patient-rated physical functioning in heart failure patients. J. Behav. Med. 2012, 35, 253-261. [CrossRef] [PubMed]

54. Zimet, G.D.; Dahlem, N.W.; Zimet, S.G.; Farley, G.K. The multidimensional scale of perceived social support. J. Pers. Assess. 1988, 52, 30-41. [CrossRef]

55. Hays, R.D.; Dimatteo, M.R. A Short-Form Measure of Loneliness. J. Pers. Assess. 1987, 51, 69-81. [CrossRef] [PubMed]

56. Thoresen, S.; Tambs, K.; Hussain, A.; Heir, T.; Johansen, V.A.; Bisson, J.I. Brief measure of posttraumatic stress reactions: Impact of Event Scale-6. Soc. Psychiatry Psychiatr. Epidemiol. 2010, 45, 405-412. [CrossRef]

57. American Psychiatric Association. Severity of Acute Stress Symptoms-Adult (National Stressful Events Survey Acute Stress Disorder Short Scale [NSESSS]); American Psychiatric Association: Washington, DC, USA, 2013.

58. Cann, A.; Calhoun, L.G.; Tedeschi, R.G.; Taku, K.; Vishnevsky, T.; Triplett, K.N.; Danhauer, S.C. A short form of the posttraumatic growth inventory. Anxiety Stress Coping 2010, 23, 127-137. [CrossRef] [PubMed]

59. Foa, E.B.; Huppert, J.D.; Leiberg, S.; Langner, R.; Kichic, R.; Haicak, G.; Salkovskis, P.M. The Obsessive-Compulsive Inventory: Development and validation of a short version-PubMed. Psychol. Assess. 2002, 14, 485-496. [CrossRef] [PubMed]

60. Giallonardo, V.; Sampogna, G.; Del Vecchio, V.; Luciano, M.; Albert, U.; Carmassi, C.; Carrà, G.; Cirulli, F.; Dell'Osso, B.; Nanni, M.G.; et al. The impact of quarantine and physical distancing following COVID-19 on mental health: Study protocol of a multicentric Italian population trial. Front. Psychiatry 2020, 11, 533. [CrossRef]

61. Goldberg, D.P.; Gater, R.; Sartorius, N.; Ustun, T.B.; Piccinelli, M.; Gureje, O.; Rutter, C. The validity of two versions of the GHQ in the WHO study of mental illness in general health care. Psychol. Med. 1997, 27, 191-197. [CrossRef] [PubMed]

62. Van Spijker, B.A.J.; Batterham, P.J.; Calear, A.; Farrer, L.; Christensen, H.; Reynolds, J.; Kerkhof, A.J. The Suicidal Ideation Attributes Scale (SIDAS): Community-based validation study of a new scale for the measurement of suicidal ideation. Suicide Life-Threat. Behav. 2014, 44, 408-419. [CrossRef] [PubMed]

63. Maslach, C.; Jackson, S.E. MBI: Maslach Burnout Inventory; Consulting Psychologist Press: Palo Alto, CA, USA, 1981.

64. Fagerland, M.W. T-tests, non-parametric tests, and large studiesa paradox of statistical practice? BMC Med. Res. Methodol. 2012, 12, 1-7. [CrossRef]

65. Ghasemi, A.; Zahediasl, S. Normality tests for statistical analysis: A guide for non-statisticians. Int. J. Endocrinol. Metab. 2012, 10, 486-489. [CrossRef] [PubMed]

66. Altman, D.G.; Bland, J.M. Statistics notes: The Normal distribution. BMJ 1995, 310, 298. [CrossRef] [PubMed] 
67. Alleaume, C.; Verger, P.; Peretti-Watel, P. Psychological support in general population during the COVID-19 lockdown in France: Needs and access. PLoS ONE 2021, 16, e0251707. [CrossRef]

68. World Health Organization. COVID-19 Disrupting Mental Health Services in Most Countries, WHO Survey 2020. Available online: https:/ / www.who.int/news/item/05-10-2020-covid-19-disrupting-mental-health-services-in-most-countries-whosurvey (accessed on 21 July 2021).

69. Chen, S.; Jones, P.B.; Underwood, B.R.; Moore, A.; Bullmore, E.T.; Banerjee, S.; Osimo, E.F.; Deakin, J.B.; Hatfield, C.F.; Thompson, F.J.; et al. The early impact of COVID-19 on mental health and community physical health services and their patients' mortality in Cambridgeshire and Peterborough, UK. J. Psychiatr. Res. 2020, 131, 244-254. [CrossRef] [PubMed]

70. Rennert-May, E.; Leal, J.; Thanh, N.X.; Lang, E.; Dowling, S.; Manns, B.; Wasylak, T.; Ronksley, P.E. The impact of COVID-19 on hospital admissions and emergency department visits: A population-based study. PLoS ONE 2021, 16, e0252441. [CrossRef] [PubMed]

71. Barney, A.; Buckelew, S.; Mesheriakova, V.; Raymond-Flesch, M. The COVID-19 Pandemic and Rapid Implementation of Adolescent and Young Adult Telemedicine: Challenges and Opportunities for Innovation. J. Adolesc. Health 2020, 67, 164-171. [CrossRef]

72. Fagiolini, A.; Cuomo, A.; Frank, E. COVID-19 Diary from a Psychiatry Department in Italy. J. Clin. Psychiatry 2020, 81, 20com13357. [CrossRef] [PubMed]

73. Unützer, J.; Kimmel, R.J.; Snowden, M. Psychiatry in the age of COVID-19. World Psychiatry 2020, 19, 130-131. [CrossRef] [PubMed]

74. Szmuda, T.; Ali, S.; Słoniewski, P.; NSurg4Wl Group. Telemedicine in neurosurgery during the novel coronavirus (COVID-19) pandemic. Neurol. Neurochir. Pol. 2020, 54, 207-208. [CrossRef]

75. Neves, A.L.; Li, E.; Gupta, P.P.; Fontana, G.; Darzi, A. Virtual primary care in high-income countries during the COVID-19 pandemic: Policy responses and lessons for the future. Eur. J. Gen. Pract. 2021, 27, 241-247. [CrossRef] [PubMed]

76. Druss, B.G. Addressing the COVID-19 pandemic in populations with serious mental illness. JAMA Psychiatry 2020, 77, 891-892. [CrossRef] [PubMed]

77. Shinn, A.K.; Viron, M. Perspectives on the COVID-19 pandemic and individuals with serious mental illness. J. Clin. Psychiatry 2020, 81. [CrossRef] [PubMed]

78. Sampogna, G.; Del Vecchio, V.; Giallonardo, V.; Luciano, M.; Albert, U.; Carmassi, C.; Carrà, G.; Cirulli, F.; Dell'Osso, B.; Menculini, G.; et al. What is the role of resilience and coping strategies on the mental health of the general population during the COVID-19 pandemic? Results from the Italian multicentric comet study. Brain Sci. 2021, 11, 1231. [CrossRef] [PubMed]

79. Robillard, R.; Daros, A.R.; Phillips, J.L.; Porteous, M.; Saad, M.; Pennestri, M.-H.; Kendzerska, T.; Edwards, J.D.; Solomonova, E.; Bhatla, R.; et al. Emerging New Psychiatric Symptoms and the Worsening of Pre-existing Mental Disorders during the COVID-19 Pandemic: A Canadian Multisite Study: Nouveaux symptômes psychiatriques émergents et détérioration des troubles mentaux préexistants pendanturant lap. Can. J. Psychiatry 2021, 66, 815-826. [CrossRef] [PubMed]

80. Montemurro, N. The emotional impact of COVID-19: From medical staff to common people. Brain Behav. Immun. 2020, 87, 23-24. [CrossRef] [PubMed]

81. Hao, F.; Tan, W.; Jiang, L.; Zhang, L.; Zhao, X.; Zou, Y.; Hu, Y.; Luo, X.; Jiang, X.; McIntyre, R.S.; et al. Do psychiatric patients experience more psychiatric symptoms during COVID-19 pandemic and lockdown? A case-control study with service and research implications for immunopsychiatry. Brain Behav. Immun. 2020, 87, 100-106. [CrossRef] [PubMed]

82. Chevance, A.; Gourion, D.; Hoertel, N.; Llorca, P.-M.; Thomas, P.; Bocher, R.; Moro, M.-R.; Laprévote, V.; Benyamina, A.; Fossati, P.; et al. Ensuring mental health care during the SARS-CoV-2 epidemic in France: A narrative review. Encephale 2020, 46, S3-S13. [CrossRef]

83. De Hert, M.; Mazereel, V.; Detraux, J.; Van Assche, K. Prioritizing COVID-19 vaccination for people with severe mental illness World Psychiatry 2021, 20, 54-55. [CrossRef] [PubMed]

84. Maj, M.; Van Os, J.; De Hert, M.; Gaebel, W.; Galderisi, S.; Green, M.F.; Guloksuz, S.; Harvey, P.D.; Jones, P.B.; Malaspina, D.; et al. The clinical characterization of the patient with primary psychosis aimed at personalization of management. World Psychiatry 2021, 20, 4-33. [CrossRef]

85. Fiorillo, A.; Sampogna, G.; Elkholy, H.; Tasman, A. Updates from the WPA Section on Education in Psychiatry. World Psychiatry 2021, 20, 149-150. [CrossRef] [PubMed]

86. Wasserman, D. Future WPA President's public mental health agenda. World Psychiatry 2021, 20, 309-320. [CrossRef] [PubMed]

87. Correll, C.U.; Solmi, M.; Veronese, N.; Bortolato, B.; Rosson, S.; Santonastaso, P.; Thapa-Chhetri, N.; Fornaro, M.; Gallicchio, D.; Collantoni, E.; et al. Prevalence, incidence and mortality from cardiovascular disease in patients with pooled and specific severe mental illness: A large-scale meta-analysis of 3,211,768 patients and 113,383,368 controls. World Psychiatry 2017, 16, 163-180. [CrossRef] [PubMed]

88. Vancampfort, D.; Firth, J.; Correll, C.U.; Solmi, M.; Siskind, D.; De Hert, M.; Carney, R.; Koyanagi, A.; Carvalho, A.F.; Gaughran, F.; et al. The impact of pharmacological and non-pharmacological interventions to improve physical health outcomes in people with schizophrenia: A meta-review of meta-analyses of randomized controlled trials. World Psychiatry 2019, 18, 53-66. [CrossRef] [PubMed] 
89. Pompili, M.; Innamorati, M.; Sampogna, G.; Albert, U.; Carmassi, C.; Carrà, G.; Cirulli, F.; Erbuto, D.; Luciano, M.; Nanni, M.G.; et al. The impact of Covid-19 on unemployment across Italy: Consequences for those affected by psychiatric conditions. J. Affect. Disord. 2022, 296, 59-66. [CrossRef]

90. Reeves, A.; Stuckler, D.; McKee, M.; Gunnell, D.; Chang, S.; Sen Basu, S. Increase in state suicide rates in the USA during economic recession. Lancet 2012, 380, 1813-1814. [CrossRef]

91. Frasquilho, D.; Matos, M.G.; Salonna, F.; Guerreiro, D.; Storti, C.C.; Gaspar, T.; Caldas-De-Almeida, J.M. Mental health outcomes in times of economic recession: A systematic literature review Health behavior, health promotion and society. BMC Public Health 2016, 16, 115. [CrossRef]

92. Knapp, M.; Wong, G. Economics and mental health: The current scenario. World Psychiatry 2020, 19, 3-14. [CrossRef] [PubMed]

93. McIntyre, R.S.; Lee, Y. Preventing suicide in the context of the COVID-19 pandemic. World Psychiatry 2020, 19, 250-251. [CrossRef] [PubMed]

94. Moretti, A.; Menna, F.; Aulicino, M.; Paoletta, M.; Liguori, S.; Iolascon, G. Characterization of home working population during COVID-19 emergency: A cross-sectional analysis. Int. J. Environ. Res. Public Health 2020, 17, 6284. [CrossRef] [PubMed]

95. Matthews, T.; Danese, A.; Caspi, A.; Fisher, H.L.; Goldman-Mellor, S.; Kepa, A.; Moffitt, T.; Odgers, C.; Arseneault, L. Lonely young adults in modern Britain: Findings from an epidemiological cohort study. Psychol. Med. 2019, 49, 268-277. [CrossRef] [PubMed]

96. Ganesan, B.; Al-Jumaily, A.; Fong, K.N.K.; Prasad, P.; Meena, S.K.; Tong, R.K.Y. Impact of Coronavirus Disease 2019 (COVID-19) Outbreak Quarantine, Isolation, and Lockdown Policies on Mental Health and Suicide. Front. Psychiatry 2021, 12, 565190. [CrossRef]

97. The Academy of Medical Sciences. COVID Mental Health Surveys. 2020. Available online: http://www.acmedsci.ac.uk/ COVIDmentalhealthsurveys (accessed on 21 July 2021).

98. Wasserman, D.; Iosue, M.; Wuestefeld, A.; Carli, V. Adaptation of evidence-based suicide prevention strategies during and after the COVID-19 pandemic. World Psychiatry 2020, 19, 294-306. [CrossRef] [PubMed]

99. Kato, T.A.; Kanba, S.; Teo, A.R. Defining pathological social withdrawal: Proposed diagnostic criteria for hikikomori. World Psychiatry 2020, 19, 116-117. [CrossRef] [PubMed]

100. Rooksby, M.; Furuhashi, T.; McLeod, H.J. Hikikomori: A hidden mental health need following the COVID-19 pandemic. World Psychiatry 2020, 19, 399-400. [CrossRef] [PubMed]

101. Varma, P.; Burge, M.; Meaklim, H.; Junge, M.; Jackson, M.L. Poor sleep quality and its relationship with individual characteristics, personal experiences and mental health during the COVID-19 pandemic. Int. J. Environ. Res. Public Health 2021, 18, 6030. [CrossRef]

102. Shrestha, D.; Adhikari, S.P.; Rawal, N.; Budhathoki, P.; Pokharel, S.; Adhikari, Y.; Rokaya, P.; Raut, U. Sleep quality among undergraduate students of a medical college in Nepal during COVID-19 pandemic: An online survey. F1000Research 2021, 10, 505. [CrossRef]

103. Yue, L.; Zhao, R.; Xiao, Q.; Zhuo, Y.; Yu, J.; Meng, X. The effect of mental health on sleep quality of front-line medical staff during the COVID-19 outbreak in China: A cross-sectional study. PLoS ONE 2021, 16, e0253753. [CrossRef]

104. Alimoradi, Z.; Broström, A.; Tsang, H.W.; Griffiths, M.D.; Haghayegh, S.; Ohayon, M.M.; Lin, C.-Y.; Pakpour, A.H. Sleep problems during COVID-19 pandemic and its' association to psychological distress: A systematic review and meta-analysis. EClinicalMedicine 2021, 36, 100916. [CrossRef]

105. Krishnan, V.; Gupta, R.; Grover, S.; Basu, A.; Tripathi, A.; Subramanyam, A.; Nischal, A.; Hussain, A.; Mehra, A.; Ambekar, A.; et al. Changes in sleep pattern and sleep quality during COVID-19 lockdown. Indian J. Psychiatry 2020, 62, 370-378. [CrossRef]

106. Abdullah, H.; Lynch, S.; Aftab, S.; Shahar, S.; Klepacz, L.; Cristofano, P.; Rahmat, S.; Save-Mundra, J.; Dornbush, R.; Lerman, A.; et al. Characteristics of Calls to a COVID-19 Mental Health Hotline in the First Wave of the Pandemic in New York. Community Ment. Health J. 2021, 57, 1252-1254. [CrossRef]

107. Yue, L.; Wang, J.; Ju, M.; Zhu, Y.; Chen, L.; Shi, L.; Shi, B.; Chen, J.; Shen, Y. How psychiatrists coordinate treatment for COVID-19: A retrospective study and experience from China. Gen. Psychiatry 2020, 33, e100272. [CrossRef]

108. Krystal, A.D.; Prather, A.A.; Ashbrook, L.H. The assessment and management of insomnia: An update. World Psychiatry 2019, 18, 337-352. [CrossRef] [PubMed]

109. Menges, D.; Ballouz, T.; Anagnostopoulos, A.; Aschmann, H.E.; Domenghino, A.; Fehr, J.S.; Puhan, M.A. Burden of post-COVID19 syndrome and implications for healthcare service planning: A population-based cohort study. PLoS ONE 2021, 16, e0254523. [CrossRef] [PubMed]

110. Bo, H.-X.; Li, W.; Yang, Y.; Wang, Y.; Zhang, Q.; Cheung, T.; Wu, X.; Xiang, Y.-T. Posttraumatic stress symptoms and attitude toward crisis mental health services among clinically stable patients with COVID-19 in China. Psychol. Med. 2020, 51, 1052-1053. [CrossRef]

111. Hong, S.; Kim, H.; Park, M.K. Impact of COVID-19 on post-traumatic stress symptoms in the general population: An integrative review. Int. J. Ment. Health Nurs. 2021, 30, 834-846. [CrossRef]

112. Benatti, B.; Albert, U.; Maina, G.; Fiorillo, A.; Celebre, L.; Girone, N.; Fineberg, N.; Bramante, S.; Rigardetto, S.; Dell'Osso, B. What Happened to Patients with Obsessive Compulsive Disorder During the COVID-19 Pandemic? A Multicentre Report from Tertiary Clinics in Northern Italy. Front. Psychiatry 2020, 11, 720. [CrossRef] [PubMed] 
113. Hassoulas, A.; Umla-Runge, K.; Zahid, A.; Adams, O.; Green, M.; Hassoulas, A.; Panayiotou, E. Investigating the Association Between Obsessive-Compulsive Disorder Symptom Subtypes and Health Anxiety as Impacted by the COVID-19 Pandemic: A Cross-Sectional Study. Psychol. Rep. 2021, 003329412110404. [CrossRef] [PubMed]

114. Fineberg, N.; Van Ameringen, M.; Drummond, L.; Hollander, E.; Stein, D.; Geller, D.; Walitza, S.; Pallanti, S.; Pellegrini, L.; Zohar, J.; et al. How to manage obsessive-compulsive disorder (OCD) under COVID-19: A clinician's guide from the International College of Obsessive Compulsive Spectrum Disorders (ICOCS) and the Obsessive-Compulsive and Related Disorders Research Network (OCRN) of the European College of Neuropsychopharmacology. Compr. Psychiatry 2020, 100, 152174. [CrossRef]

115. Janiri, D.; Moccia, L.; Dattoli, L.; Pepe, M.; Molinaro, M.; De Martin, V.; Chieffo, D.; Di Nicola, M.; Fiorillo, A.; Janiri, L.; et al. Emotional dysregulation mediates the impact of childhood trauma on psychological distress: First Italian data during the early phase of COVID-19 outbreak. Aust. N. Z. J. Psychiatry 2021, 0004867421998802. [CrossRef]

116. Moccia, L.; Janiri, D.; Pepe, M.; Dattoli, L.; Molinaro, M.; De Martin, V.; Chieffo, D.; Janiri, L.; Fiorillo, A.; Sani, G.; et al. Affective temperament, attachment style, and the psychological impact of the COVID-19 outbreak: An early report on the Italian general population. Brain Behav. Immun. 2020, 87, 75-79. [CrossRef]

117. Tyrer, P. COVID-19 health anxiety. World Psychiatry 2020, 19, 307-308. [CrossRef] [PubMed]

118. Nshimyiryo, A.; Barnhart, D.A.; Cubaka, V.K.; Dusengimana, J.M.V.; Dusabeyezu, S.; Ndagijimana, D.; Umutesi, G.; Shyirambere, C.; Karema, N.; Mubiligi, J.M.; et al. Barriers and coping mechanisms to accessing healthcare during the COVID-19 lockdown: A cross-sectional survey among patients with chronic diseases in rural Rwanda. BMC Public Health 2021, 21, 1-11. [CrossRef] [PubMed]

119. Brown, S. Perinatal mental health and the COVID-19 pandemic. World Psychiatry 2020, 19, 333-334. [CrossRef] [PubMed]

120. Gagliardi, A.R.; Yip, C.Y.Y.; Irish, J.; Wright, F.C.; Rubin, B.; Ross, H.; Green, R.; Abbey, S.; McAndrews, M.P.; Stewart, D.E. The psychological burden of waiting for procedures and patient-centred strategies that could support the mental health of wait-listed patients and caregivers during the COVID-19 pandemic: A scoping review. Health Expect. 2021, 24, 978-990. [CrossRef] [PubMed]

121. Wang, Q.Q.; Xu, R.; Volkow, N.D. Increased risk of COVID-19 infection and mortality in people with mental disorders: Analysis from electronic health records in the United States. World Psychiatry 2021, 20, 124-130. [CrossRef] [PubMed] 